Research paper

\title{
Optimizing the spatial arrangement of trees in residential neighborhoods for better cooling effects: Integrating modeling with in-situ measurements
}

\author{
Zhifeng $\mathrm{Wu}^{\mathrm{a}, \mathrm{b}}$, Liding Chen ${ }^{\mathrm{a}, *}$ \\ a State Key Laboratory of Urban and Regional Ecology, Research Center for Eco-Environmental Sciences, Chinese Academy of Sciences, Beijing 100085, China \\ b University of Chinese Academy of Sciences, Beijing 100049, China
}

\section{A R T I C L E I N F O}

\section{Keywords:}

Urban green space

Spatial configuration

Urban heat island

Solar radiation

High-rise building area

Numerical modeling

\begin{abstract}
A B S T R A C T
Trees have long been recognized as effective for mitigating urban heat islands by reducing air temperature through evapotranspiration and intercepting shortwave radiation that heat up land surfaces. Many studies have shown that both the composition and configuration of vegetation can contribute to heat reduction at the city scale. Fewer studies, however, have focused on cooling mechanisms at the neighborhood scale. Here, we integrate modeling with in situ measurements to investigate how different spatial arrangements of trees in residential neighborhoods affect their cooling effects. We conducted the research in a residential neighborhood with high-rise apartment buildings in Beijing. We tested four scenarios with different spatial arrangements of trees, and quantified their effects on cooling. We used the high spatial and temporal resolution microclimate model ENVI-met and validated the model with in situ measurements. We found: (1) Different spatial arrangements had differentiated effects on intercepting shortwave radiation, which led to variations in air temperature. For example, new trees that were completely exposed to solar radiation had stronger cooling effects (air temperature was $0.22{ }^{\circ} \mathrm{C}$ lower) than new trees that were located in the shadow of surrounding buildings. (2) Different spatial arrangements led to obviously different effects of sensible heat reduction, with a maximum difference of $14.84 \times 10^{8} \mathrm{~J} / \mathrm{ha}$. Our results underscore the importance of the spatial arrangement of trees on cooling in residential neighborhoods. These results have important implications in urban planning and design at the neighborhood scale.
\end{abstract}

\section{Introduction}

Urbanization leads to radical changes in land surfaces and the atmosphere, which involves the transformation of radiation, heat and moisture, and consequently produces energy exchanges that are distinctly different from rural areas (Oke, 1987). Natural landscapes are massively replaced by complex impervious alternatives that not only absorb large amounts of solar radiation but also trap both incident shortwave and outgoing long-wave radiation from escaping to the atmosphere (Oke, 1982). Moreover, impervious surfaces prevent the infiltration of water into the soil, which reduces evapotranspiration and increases sensible heating of the local ambient air (Coutts, Beringer, \& Tapper, 2007). Such modifications of land surfaces and energy exchanges from urbanization give rise to the urban heat island (UHI), which is a phenomenon in which cities are on average warmer than the surrounding rural areas. The UHI is among the most evident aspects of human impacts on the earth system, and it has been documented in large and small urban areas worldwide (Peng et al., 2012). Urban warming can have substantial impacts on energy consumption, air and water quality and human health, particularly considering climate change, and more frequent and longer lasting heat waves (Meehl \& Tebaldi, 2004). Therefore, it is of critical importance to improve the urban environment by managing and planning its land use pattern.

Strategies commonly applied to existing urban areas often focus on ameliorating deleterious effects of UHI, such as by using cool pavement/high albedo pavement, permeable concrete or asphalt, and increasing greenspace. Increasing vegetation, especially trees, is particularly favored by urban planners and designers because vegetation can simultaneously lower sensible heat and increase latent heat flux into the atmosphere (Georgescu et al., 2015). In addition, vegetation can provide important ecosystem services, such as regulating urban stormwater, sequestering carbon, and improving health and aesthetics (de Sousa, Montalto, \& Palmer, 2016). Previous studies have shown that both the composition and configuration of vegetation affect its cooling effects (Connors, Galletti, \& Chow, 2013; Du, Xiong, Wang, \& Guo, 2016; Li, Zhou, \& Ouyang, 2013; Li, Zhou, Ouyang, Xu, \& Zheng, 2012; Zhou, Huang, \& Cadenasso, 2011). With limited space available in

\footnotetext{
* Corresponding author

E-mail addresses: liding@rcees.ac.cn, chenliding@sohu.com (L. Chen).
} 


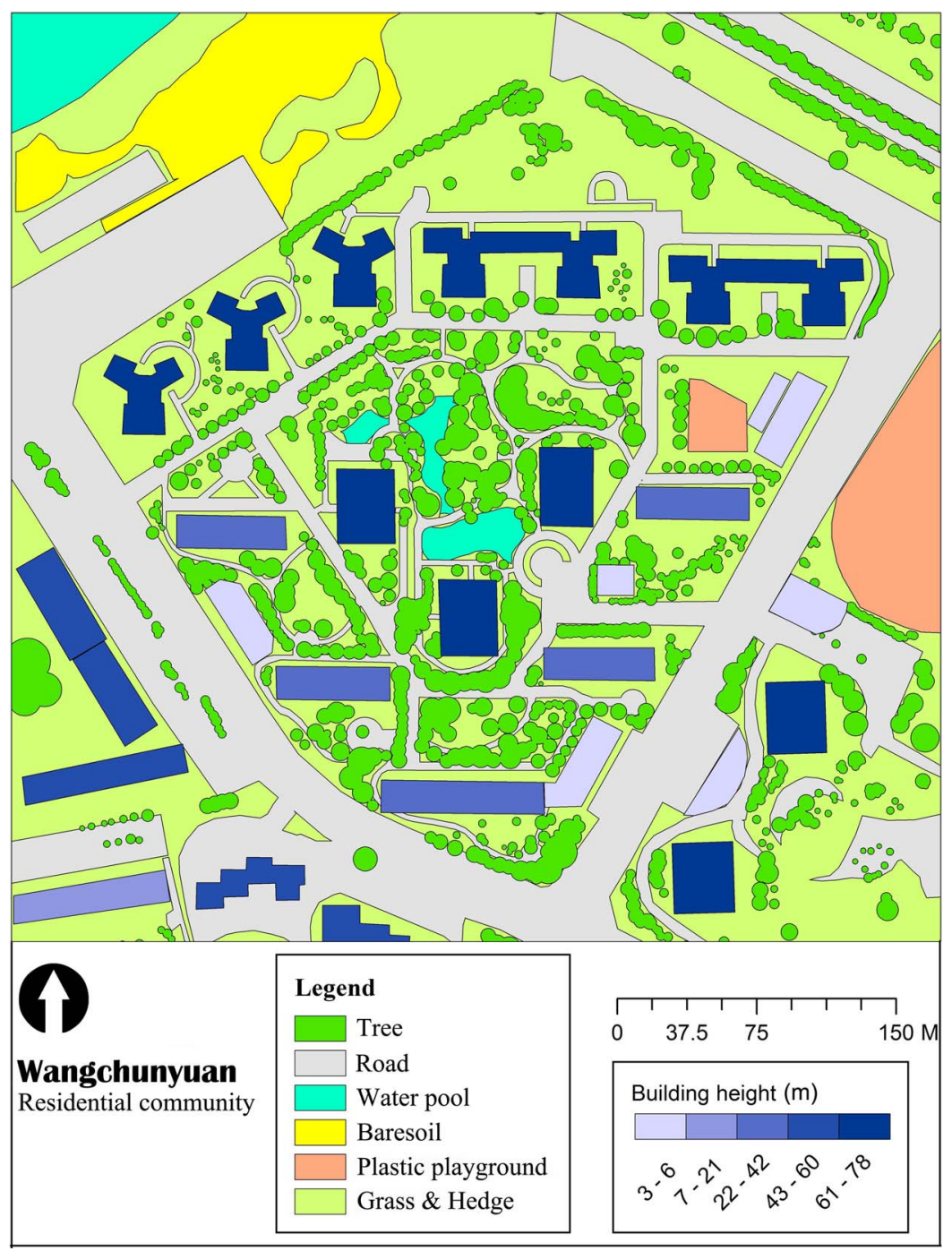

Fig. 1. Land cover types of WCY and its surrounding area.

developed urban areas for greening, a frequently asked question is how to optimize the spatial arrangement of vegetation for improved cooling effects.

Previous studies have shown that the spatial configuration of greenspaces affects the UHI magnitude (Li et al., 2011; Liu \& Weng, 2008; Zhou et al., 2011). Indices derived from landscape ecology, such as patch density and edge density, were usually used to represent the cooling effect of different spatial configurations of greenspaces. Specifically, patch density of greenspaces has a significant positive relationship with surface temperature, meaning that an increase in patch density will lead to higher UHI magnitude (Li et al., 2013). Kong, Yin, James, Hutyra, and He (2014) indicated that a large greenspace patch may enhance the cooling effects of nearby smaller greenspaces. They suggested using multiple small greenspaces in urban planning to improve the urban thermal environment. In contrast, an increase of edge density would help to lower the UHI magnitude (Zhou et al., 2011). These studies were generally based on land surface temperature derived from remote sensing data, such as Landsat-7 ETM + (Enhanced Thematic Mapper Plus) images, which has a spatial resolution $(60 \mathrm{~m}$ for thermal infrared band) that is still too coarse for detailed description of landscape configuration at a neighborhood scale. At the neighborhood or block scale, more attention was given to air temperature variation obtained from field measurements or numerical simulations. However, there is no consistent relationship between land surface temperature and ambient air temperature, which limits the scaling-down of these findings from city to neighborhood scale. These findings may support better decisions on spatial arrangement of greenspaces at the city scale. On the neighborhood scale, however, urban planners and designers need more specific principles to arrange the greenspaces. As a main living space, the thermal environment of the residential community has drawn increasing interest from multiple disciplines (Wang, 2006; Wang, Zhang, Zhao, He, \& Li, 2011; Yang, Lau, \& Qian, 2010; Yang, Yan, Xu, \& Lam, 2013). However, the thermal condition of the residential community in Beijing remains largely unexamined.

Here, we investigate how different spatial arrangements of trees affect their cooling effects in residential neighborhood by integrating modeling with in situ measurements. We conducted the research in a residential neighborhood with high-rise apartment buildings in Beijing. We tested four scenarios with different spatial arrangements of trees and quantified their effects on cooling. We used the high spatial and temporal resolution microclimate model ENVI-met, and validated the model with in situ measurements. The results from this study have important implications in urban planning and designing at the neighborhood scale.

\section{Material and methods}

\subsection{Study area}

Beijing has undergone rapid urbanization over the last 30 years, with the urban area expanding from $801 \mathrm{~km}^{2}$ in $1980-2,452 \mathrm{~km}^{2}$ in 2010 (Wu, Zhao, Zhu, \& Jiang, 2015), and the population increasing 
sharply from 8.7 million in 1978-21.1 million in 2013 (Jia, 2014). Ongoing urbanization has posed great pressure on the urban thermal environment. Liu, Ji, Zhong, Jiang, and Zheng (2007) compared the air temperature between urban and rural areas of Beijing and indicated that the UHI effect has progressively intensified for decades (Liu et al., 2007). The municipal government of Beijing has implemented the Green Growth Strategy through greenbelt construction and large-scale urban forestation and the per capita area of public green space has increased from $5.0 \%$ in $1978-15.7 \%$ in 2013. However, degradation of Beijing's urban thermal environment shows no sign of retreat (Ge, Zhang, Wang, Tian, \& Feng, 2016).

In this study, a typical high-rise residential quarter, known as Wangchunyuan (WCY), in northern Beijing was selected for detailed evaluation of thermal performance from different greening modification scenarios. In the present paper, the thermal performance refers to the variation of ambient air temperature and sensible heat release from land surfaces. WCY consists of 8 buildings with 26 stories and 5 buildings with 14 stories, accommodating approximately 3500 households in total (Fig. 1). Grassland occupied the largest area in WCY, followed by roads, trees and buildings. The areas of playground and water pool are rather small, so they were not considered as important factors on the variation of the outdoor thermal environment (Table 1).

\subsection{Methods}

There were mainly three methods involved in this study: an on-site measurement of the microclimate; an estimation of incident shortwave radiation at land surfaces; and a numerical simulation of thermal environment with different vegetation arrangements. The on-site measurement program was designed to measure the microclimate conditions in the residential quarter. The measured results were used to verify the accuracy of the results of other two methods. The second method was designed to calculate the incident shortwave radiation at land surfaces over a given period of time. The estimation results provided a basis for the development of vegetation arrangement scenarios in the numerical simulation. The numerical simulation was applied to simulate and predict the cooling effects of different vegetation arrangement scenarios with the ENVI-met model.

\subsubsection{On-site measures of microclimate}

In this study, on-site field measures were conducted from August 10th to 18th, 2014. This period was selected to obtain various climatic data for typical summer days. An Onset $\mathrm{HOBO}^{\circ} \mathrm{U} 30$ weather station was placed in an open space at the center of a pocket park in WCY with $>10 \mathrm{~m}$ away from surrounding trees and buildings. This meteorological station measured a wide range of weather parameters, including air temperature, relative humidity, wind speed and direction, and shortwave solar radiation. The sensors connected to this station were approximately $2 \mathrm{~m}$ above ground to represent climatic conditions at pedestrian level. Six НОВО ${ }^{\circ}$ pro v2 loggers were mounted on tree trunks or electrical poles at the height of $2 \mathrm{~m}$. The data from the station and loggers were all used to verify the modeled results of ENVI-met on the selected day.

\subsubsection{Estimation of solar energy potential on land surfaces}

Land surface incident shortwave radiation is strongly influenced by the shadow effect of adjacent buildings, so shorter distances to the building are correlated with greater influence from building shadows.

Table 1

The area and percentage of land cover types of WCY.

\begin{tabular}{lllllll}
\hline Land cover types & Building & Road & Playground & Grassland & Tree & Water \\
\hline Area (ha) & 2.02 & 2.30 & 0.11 & 4.60 & 2.41 & 0.21 \\
Percentage (\%) & 17.81 & 20.43 & 0.94 & 40.55 & 18.40 & 1.87 \\
\hline
\end{tabular}

Complex urban construction results in a redistribution of downward shortwave radiation at land surfaces, which leads to highly spatially heterogeneous surface fluxes that significantly affect the local climate (Oke, 1987).

In this study, we estimated the incident shortwave radiation at land surfaces of a typical summer daytime. The basic algorithm of solar radiation estimation is implemented in terms of the approach presented by Yan and Zhao (1986). The transmittance of atmosphere is estimated with Eqs. (1) and (2). The incident shortwave radiation is the sum of direct and diffuse irradiance (3). The direct and diffuse irradiance are calculated with Eqs. (4) and (5):

$I_{\text {standard }}=I_{0} \cdot e^{-K \cdot x}$

$P=I_{\text {measured }} / I_{\text {standard }}$

$I_{\text {estimatedsum }}=I_{\text {estimateddirect }}+I_{\text {estimateddiffuse }}$

$I_{\text {estimated direct }}=I_{0} \cdot P^{1 / \text { sinh }} \cdot \cos \theta$

$I_{\text {estimated diffuse }}=-0.5 \cdot I_{0} \cdot \sinh \cdot \frac{1-P^{1 / \sinh }}{1-1.4 \ln P}$

where $I_{O}$ is the solar constant with a value of $1367 \mathrm{~W} / \mathrm{m}^{2} ; K$ is the extinction coefficient referring to the measure of the absorption of light through atmosphere by water vapor and aerosol; $x$ is the distance of light travelling through the atmosphere, which can be calculated with solar altitude $(h)$ and solar incidence angle $(\theta) ; I_{\text {standard }}$ is the solar radiation striking earth surface under the assumption of completely apparent atmosphere $(K=1) ; I_{\text {measured }}$ is the solar radiation measurement at study area. $P$ is transmittance of atmosphere that is estimated by comparing measured and predicted solar radiance; $I_{\text {estimated_sum, }}$ $I_{\text {estimated_direct }}$ and $I_{\text {estimated_diffuse }}$ are estimated total solar radiation, estimated direct solar radiation and estimated diffuse radiation reaching at land surfaces, respectively.

The digital surface model (DSM) of the study area was built on ArcGIS ${ }^{\oplus}$ platform. Coupling the spatial analysis function of ArcGIS ${ }^{\circ} 10.2$ and the algorithms stated previously, we obtained the continuous incident shortwave radiation casting on land surfaces of the study area of the modeled day (Fig. 2a).

\subsubsection{Numerical simulation of thermal environment}

ENVI-met was selected to model the thermal environmental variation. It has high spatial $(0.5-10 \mathrm{~m})$ and temporal resolution $(10 \mathrm{~s})$ and is suitable for microclimate studies at the neighborhood scale. ENVI-met is a three-dimensional and non-hydrostatic prognostic numerical model with computational fluid dynamics as its core process. It can simulate surface-plant-air interactions regarding shortwave radiation fluxes from the sun to artificial surfaces and vegetation, longwave radiation from surfaces back to the sky, and latent heat fluxes from vegetation into ambient air. Numerous outputs of the model enable researchers to investigate the evolution of microenvironment in detail. ENVI-met has been widely used and validated for assessing built environments (Berkovic, Yezioro, \& Bitan, 2012; Carfan, Galvani, \& Nery, 2012; Ghaffarianhoseini, Berardi, \& Ghaffarianhoseini, 2015; Johansson, Onomura, Lindberg, \& Seaquist, 2015; Middel, Chhetri, \& Quay, 2014; Taleghani, Sailor, Tenpierik, \& van den Dobbelsteen, 2014).

The ENVI-met is composed of a 1D border model and a 3D core model, which includes atmospheric, vegetation and soil sub-models. Each of these models or sub-models was designed to deal with some specific processes. The atmospheric sub-model, which is mainly based on the fundamental laws of computational fluid dynamics, prognoses the evolution of the wind flow, air temperature and humidity, and turbulence. The absorption and emission of short-wave and long-wave radiations are also involved in this sub-model. The soil sub-model is mainly in charge of calculating the temperature and humidity at the ground surface and underground to a certain depth. This sub-model 


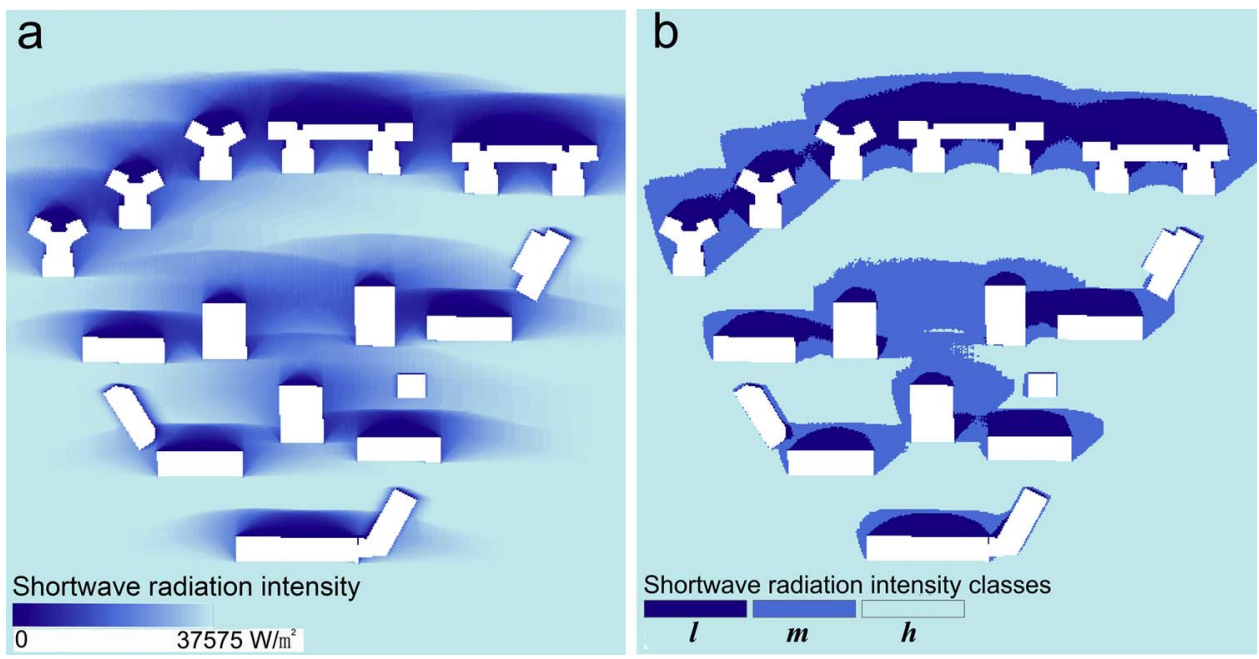

Fig. 2. Shortwave radiation at land surface of WCY. a: Shortwave radiation intensity; b: Classes of shortwave radiation intensity. takes into account the hydrological and thermo-dynamical processes which vary in accordance with the individual soil properties. Vegetation sub-model deals with all the ecological processes related to vegetation system. In ENVI-met, vegetation is not just physical obstacles against wind and radiation but also biological bodies which interacts with surrounding environment by exchanging heat and water vapor.

The ENVI-met model is governed by numerous equations with complex terms. Model users perform their simulations by designing building morphology and vegetation patterns and modifying initial meteorological conditions and thermo-physical properties of land covers. Table 2 shows the main input parameters including thermalphysical properties of main land covers.

To represent the configuration of buildings and greenspaces of WCY as precisely as possible, we defined the area input file combining field measurements and high-resolution WorldView-2 images. The height of each building was measured using a laser hypsometer (OPTI-LOGIC 400XT). The maximum building height in the WCY was $78 \mathrm{~m}$. A main model domain area representing the current conditions of the study area was built within $235 \times 235 \times 25$ grids, with input dimensions of $d x, d y=2 \mathrm{~m}$ and $d z=5 \mathrm{~m}$. In addition to the WCY residential quarter area, the surrounding buildings and vegetation were also included in the model to create a more realistic wind environment. Furthermore,

Table 2

The main input parameters of the ENVI-met simulation.

\begin{tabular}{|c|c|c|}
\hline Items & & $\begin{array}{l}\text { User Input during } \\
\text { simulations }\end{array}$ \\
\hline Simulation day & & 11 August 2014 \\
\hline Simulation time & & $24 \mathrm{~h}$ \\
\hline Initial temperature $\left({ }^{\circ} \mathrm{C}\right)$ & & 24.5 \\
\hline $\begin{array}{l}\text { Relative humidity } 2 \mathrm{~m} \\
\text { aboveground }\end{array}$ & & $45 \%$ \\
\hline Wind speed $(\mathrm{m} / \mathrm{s})$ & & 1.5 \\
\hline Wind direction & & $220^{\circ}$ \\
\hline Indoor temperature & & $19^{\circ} \mathrm{C}$ \\
\hline $\begin{array}{l}\text { Heat transmission of walls/roofs } \\
\qquad\left(\mathrm{W} / \mathrm{m}^{2}\right)\end{array}$ & & $1.7 / 2.0$ respectively \\
\hline Albedo of walls/roofs & & $0.3 / 0.4$ respectively \\
\hline \multirow{4}{*}{$\begin{array}{l}\text { Volumetric heat capacity ( } \mathrm{J} / \\
\left.\mathrm{m}^{3} \mathrm{~K} \times 10^{-6}\right)\end{array}$} & Asphalt & 2.214 \\
\hline & Cement & 2.088 \\
\hline & Concrete & \\
\hline & Loamy soil & 1.212 \\
\hline \multirow[t]{4}{*}{ Heat conductivity(W/m K) } & Asphalt & 1.16 \\
\hline & Cement & 1.63 \\
\hline & Concrete & \\
\hline & Loamy soil & - \\
\hline
\end{tabular}

we added five nesting grids to each side of the model area to increase the stability of the simulation for elements close to the border of the study area.

The incident shortwave irradiance at land surface of WCY obtained from Section 2.2.2 was classified into three equal categories, with $h, m, l$ representing high, medium and low energy density, respectively (Fig. 2b). We first developed a scenario based on the current conditions of green spaces of WCY, which was used as the base case. Then, three other vegetation arrangement scenarios were built to evaluate the cooling and energy-saving potential by adding vegetation at different locations of the study area. The base case (CS) has a green coverage ratio of $58.95 \%$, with proportional cover of $40.55 \%$ and $18.40 \%$ for lawns and tree canopy, respectively. We tested three scenarios, HT, MT and LT, which added the same percentage $(10 \%)$ of trees to the areas of $h, m$, and $l$, respectively, based on the base case (Fig. 3).

\subsection{Estimation of sensible heat reduction}

Air temperature changes are commonly accompanied with energy variations, which is also the fundamental issue that produces the UHI phenomena. Evapotranspiration from vegetation, in combination with shading effects, can lower ambient air temperatures by reduction in the sensible heat fluxes into the atmosphere. In this study, we calculated the sensible heat reduction of different vegetation arrangement scenarios based on the Eq. (6):

$\Delta \mathrm{E}=C_{p} \cdot \Delta T \cdot \rho \cdot V$

where $\Delta \mathrm{E}$ is the energy variation $(\mathrm{J}) ; C_{p}$ is the specific heat of air, which was set as $1.005 \mathrm{~J} /(\mathrm{g} \mathrm{K}) ; \Delta T$ is the air temperature changes; $\rho$ is air density; and $V$ is the air volume of different atmospheric layers.

Exposure to elevated surface air temperature can result in a series of consequences on human health that range from mild discomfort to lifethreatening conditions, especially for vulnerable groups such as the elderly, children, and people with heat-related diseases (Son, Lane, Lee, \& Bell, 2016; Tan et al., 2010). Previous studies tended to focus on the pedestrian level thermal environment, which is directly related to inhabitants' outdoor thermal comfort (Middel et al., 2014; Skelhorn, Lindley, \& Levermore, 2014; Srivanit \& Hokao, 2013). However, the cooling effects of vegetation affect not only the near surface thermal environmental layer but also higher atmospheric layers. In this study, we analyzed the thermal environmental variations caused by different vegetation arrangement patterns from pedestrian level to roof level. We sliced the space into different atmospheric layers in accordance to the heights of buildings, trees and people (Fig. 4). In Fig. 4A and B represent the layers indirectly affected by trees, which C1 and C2 are represent the layers directly influenced by shading effects and 

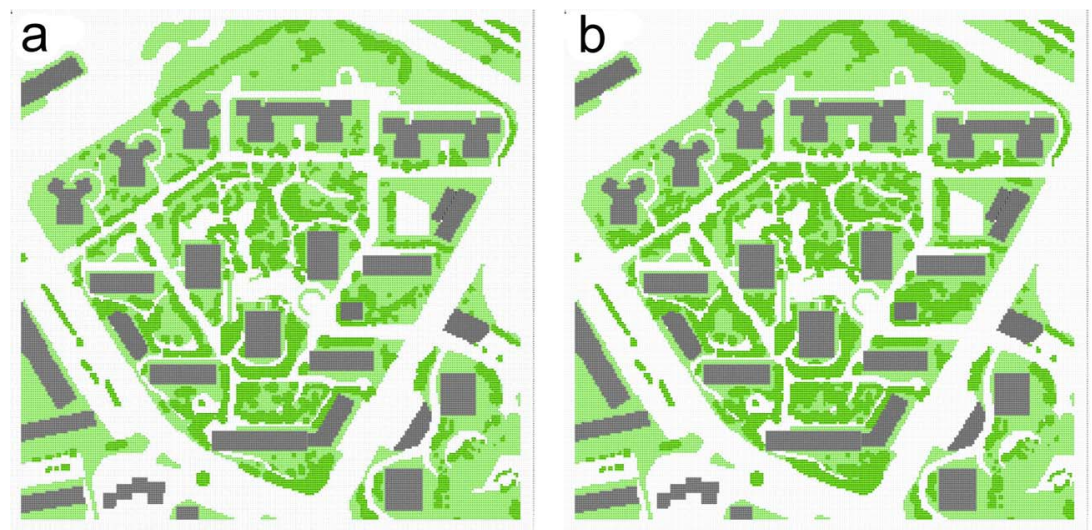

Fig. 3. Vegetation arrangement scenarios. a: Scenario CS, the base case; b: Scenario HT; c: Scenario MT; and d: Scenario LT.
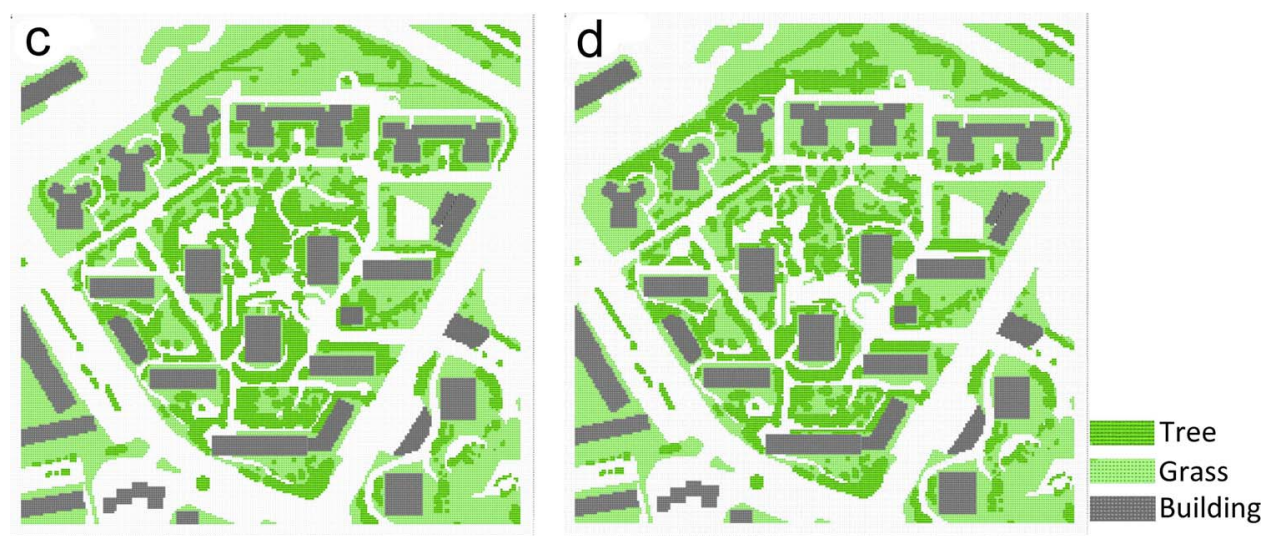

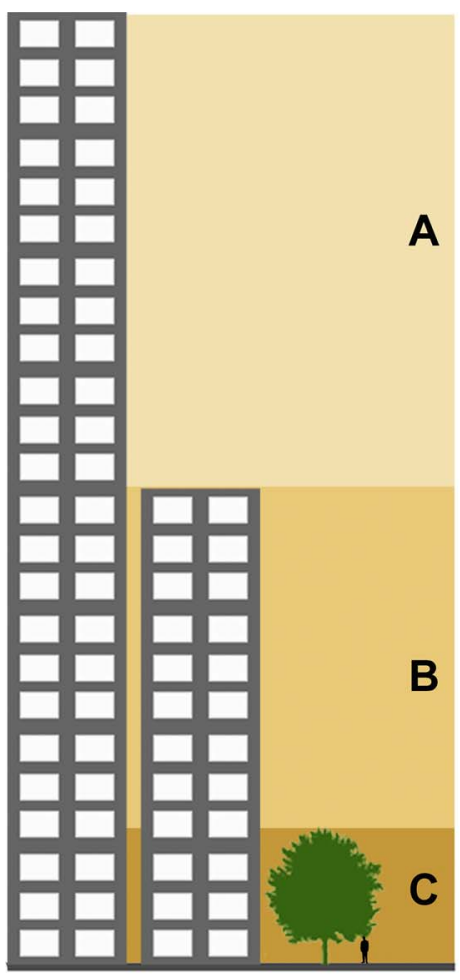

a

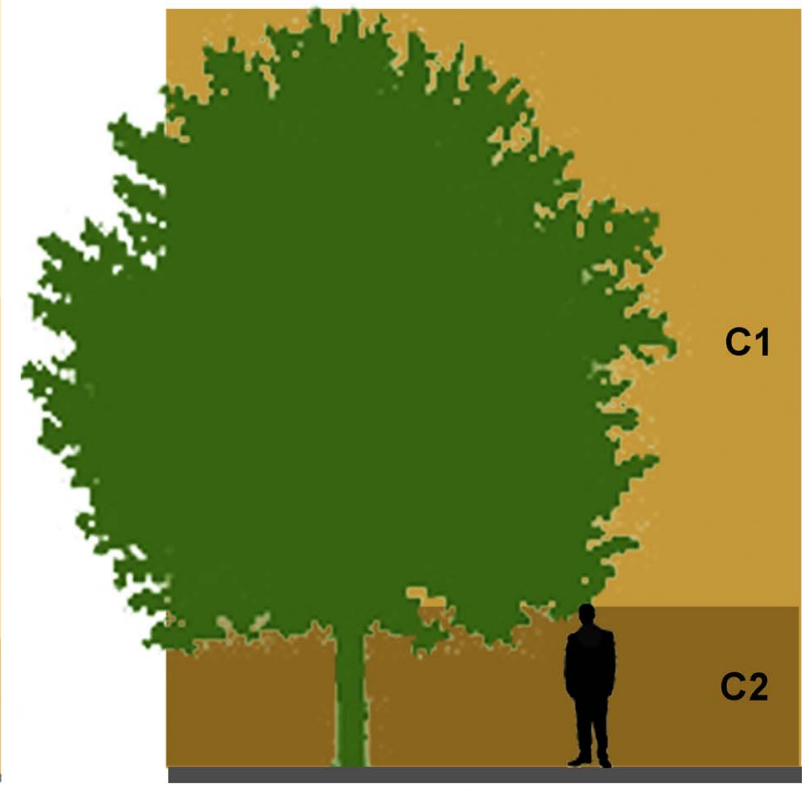

b
Fig. 4. The schematic plot of atmospheric layers. 
Table 3

The boundaries of different atmospheric layers.

\begin{tabular}{lllll}
\hline Space layers & A & B & C1 & C2 \\
\hline Upper boundary from surface (m) & 78 & 42 & 10 & 2 \\
Lower boundary from surface (m) & 42 & 10 & 2 & 0
\end{tabular}

evapotranspiration process of trees. The vertical boundaries of the layers are shown in Table 3.

\section{Results}

\subsection{Model validation}

Verifications of the two models mentioned in Sections 2.2.2 and 2.2.3 were conducted based on field measurement data. We chose August 14, 2014 to estimate the incident shortwave irradiance at land surface and to model the thermal performance of different vegetation arrangement strategies. It was a clear day with little influence from cloud and haze on solar radiation and thermal environment variation.

Fig. 5 shows the comparison of the measured and predicted shortwave solar irradiance at land surface from 7:00 to 18:00. The model performed better during $10: 00$ to $17: 00$, with the residual error ratio (RER) $\left(\frac{I_{\text {estimated_sum }}-I_{\text {measured }}}{I_{\text {measured }}} \times 100 \%\right)$ varying between $1.1 \%(15: 00)$ to $4.6 \%$ (16:00), than the hours before 10:00 and after 17:00, particularly at 6:00 to 8:00. The average difference between measured and predicted results was $21.1 \mathrm{~W} / \mathrm{m}^{2}$. These results indicate that the empirical model could meet the research requirements for estimating incident shortwave irradiance.

Fig. 6 represents the difference between measured and modeled air temperatures at $2 \mathrm{~m}$ above ground. The measured temperatures were hourly averaged data from mobile meteorological station and 6 temperature loggers. The modeled temperature refers to the mean air temperature at $2 \mathrm{~m}$ above ground of the whole WCY simulation area. Both measured and predicted air temperature peaked at 15:00 with different rates of change. The measured temperature increased $1.12{ }^{\circ} \mathrm{C}$ per hour during 7:00-15:00 and decreased $0.66{ }^{\circ} \mathrm{C}$ per hour after 15:00. Simulation results showed a lower rate of change in both the warmingup $\left(0.86{ }^{\circ} \mathrm{C} /\right.$ hour $)$ and cooling-down periods $\left(-0.39^{\circ} \mathrm{C} / \mathrm{h}\right)$. Previous studies have reported that ENVI-met produced temperatures with lower variance (Chow \& Brazel, 2012; Duarte, Shinzato, Gusson, \& Alves, 2015), which might be explained by inaccuracies in simulation input of surface thermos-physical properties and vegetation conditions.

The root mean square error (RMSE), mean average error (MAE), mean bias error (MBE) and the index of agreement (d) were calculated to evaluate the simulation results accuracy. According to results, the
RMSE is $1.05^{\circ} \mathrm{C}$ and MAE and MBE are $0.95{ }^{\circ} \mathrm{C}$ and $-0.49{ }^{\circ} \mathrm{C}$, respectively. The index of agreement was 0.93 , which indicates that even with the lower variance and underestimation of peak daytime temperature, modeled air temperature at $2 \mathrm{~m}$ above ground showed generally good agreement with field measurements.

\subsection{Comparison of air temperatures between different vegetation patterns}

We extracted $2 \mathrm{~m}$ air temperatures from 9:00 to 18:00 from the four scenarios of ENVI-met simulation of August 14, 2014. This time period was selected because it represented almost $90 \%$ of incident shortwave irradiance at land surface.

We summarized the average air temperatures at the pedestrian level (C2 layer) from 9:00 to 18:00 in relationship with vegetation arrangement scenarios (Fig. 7). All four scenarios represented similar variation ranges (Averaged air temperature \pm 1 Standard deviation). The vegetation arrangement scenarios (LT, MT and HT) had lower values of average air temperature than the base case, with temperature differences of $0.05{ }^{\circ} \mathrm{C}, 0.10^{\circ} \mathrm{C}$ and $0.22^{\circ} \mathrm{C}$, respectively. Shortwave radiation is the main energy source for heating up land surface, resulting in the rise of near surface air temperature. The LT scenario exposed to the least incident shortwave radiation because of the shading effects from adjacent high-rise buildings, comparing with other two scenarios. Canopies of newly added trees in the LT scenario hence are incapable of intercepting enough solar radiation, which explains its marginal cooling effect. However, MT and HT scenarios with trees planted in specific locations can intercept significantly more incident shortwave radiation, resulting in lower air temperatures than the LT scenario. These results indicated that changing the vegetation arrangement could produce different thermal environments.

When looking at air temperatures of different atmospheric layers, all scenarios showed reduced temperature with altitude. The temperature differences between the three vegetation arrangement scenarios with the base case grew modestly from pedestrian to upper levels. Taking the HT scenario as an example, its temperature differed from the base case, as the $\mathrm{C} 2$ to A layer increased from $0.29{ }^{\circ} \mathrm{C}$ to $0.33^{\circ} \mathrm{C}$. The results showed that vegetation arrangement could influence the near surface thermal environment, as well as the thermal conditions of higher layers (Fig. 8).

\subsection{Comparison of reduction in sensible heat between different vegetation} patterns

Fig. 9 showed the total sensible heat reduction of all the layers caused by different patterns of vegetation arrangement. From 9:00 to 18:00, the LT, MT and HT scenarios reduced $0.103 \times 10^{8} \mathrm{~kJ}$,

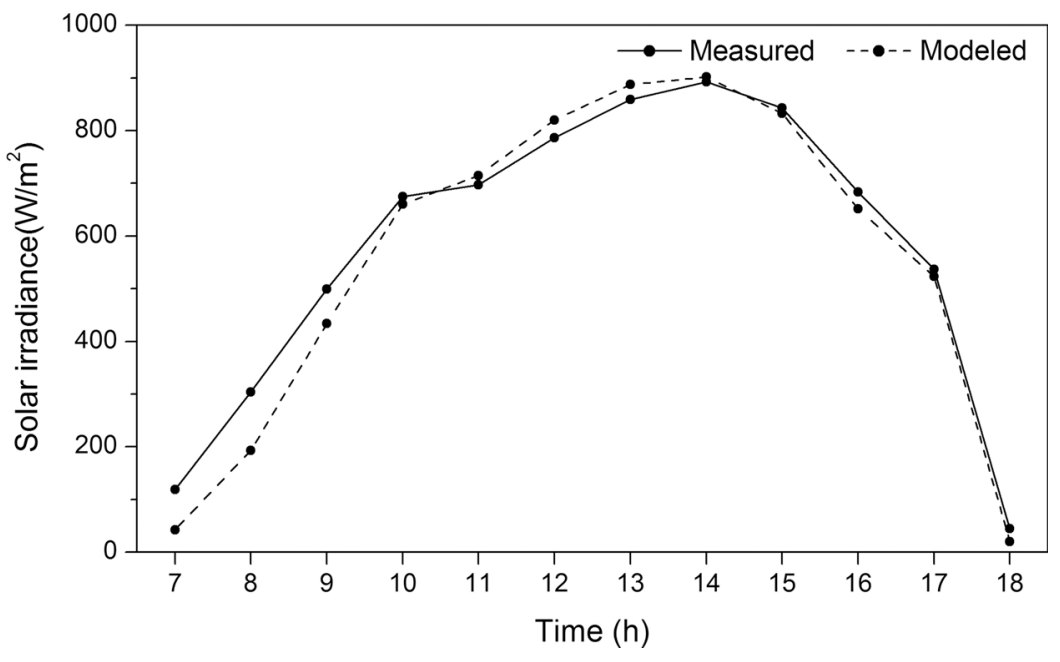

Fig. 5. Comparison of measured and predicted solar irradiance at land surface. 

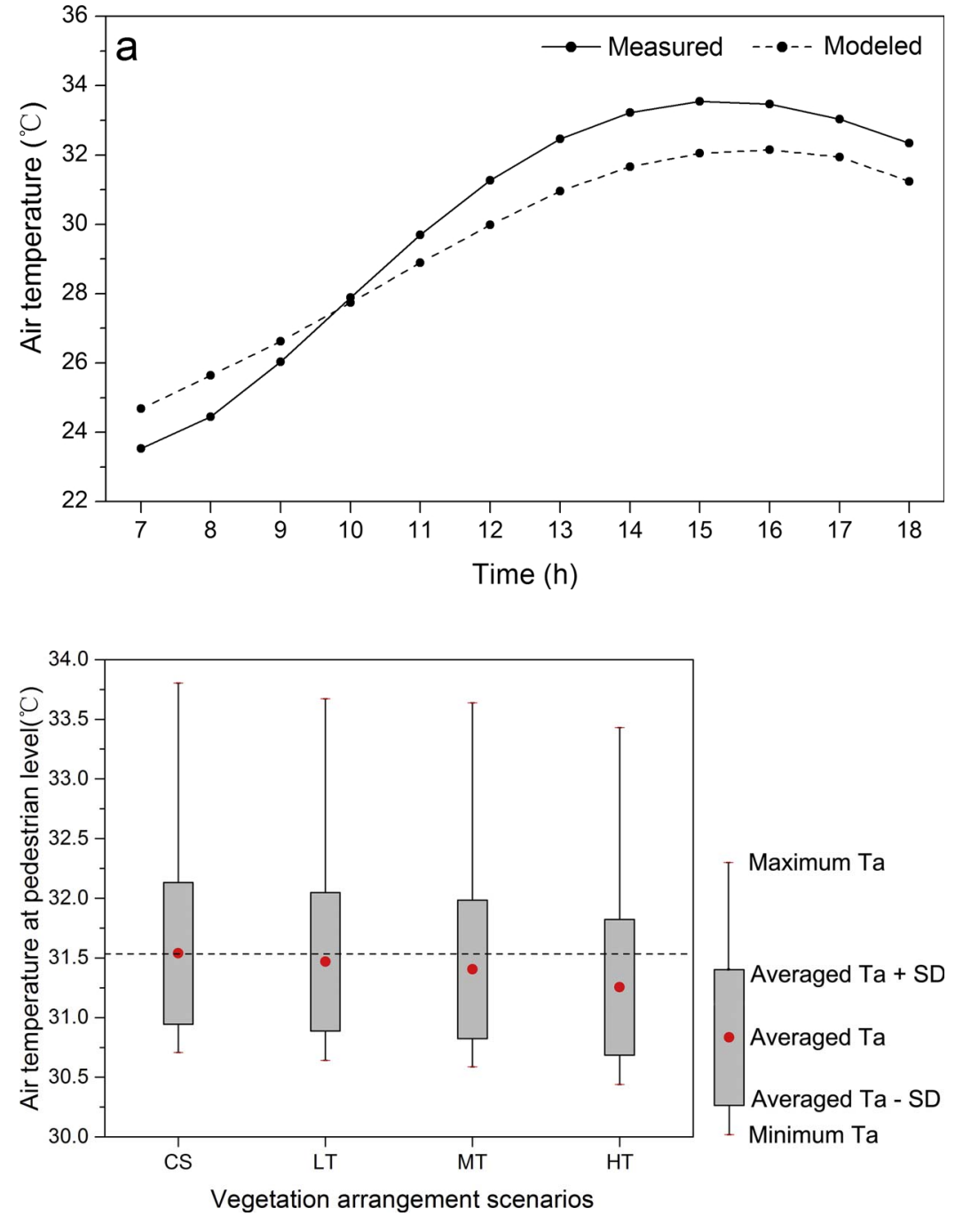

Fig. 6. Comparison of measured and modeled air temperature at $2 \mathrm{~m}$ above ground.

Fig. 7. Air temperature variations of $\mathrm{C} 2$ layer in four scenarios.

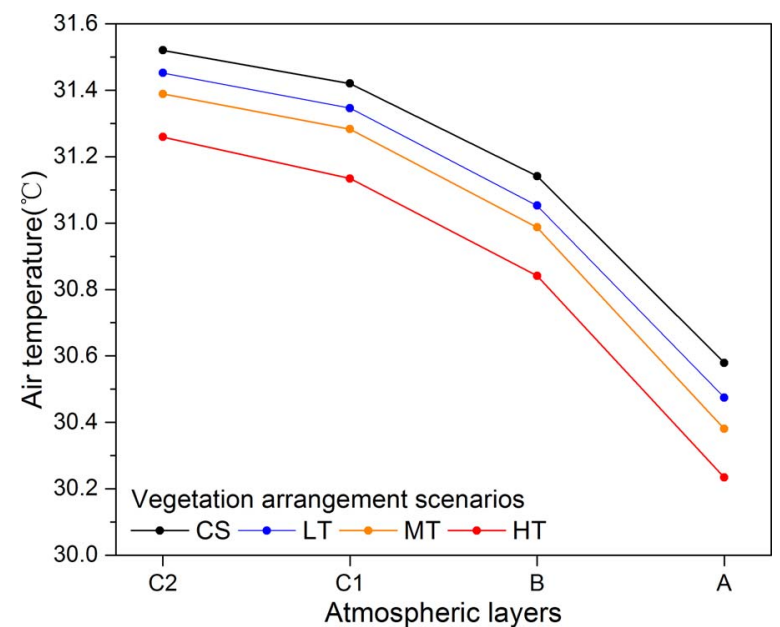

Fig. 8. Air temperatures of four vegetation arrangement scenarios of atmospheric layers.

$0.237 \times 10^{8} \mathrm{~kJ}$ and $0.406 \times 10^{8} \mathrm{~kJ}$ sensible heat into ambient atmosphere, respectively. Although newly added trees were all located in areas with the least solar radiation, these trees still contributed $5.8 \times 10^{8} \mathrm{~J} /$ ha sensible heat reduction, which should result from the evapotranspiration process of trees. The HT scenario, in which canopies of added trees were exposed to solar radiation during the daytime without any sheltering from buildings, led to a much larger sensible

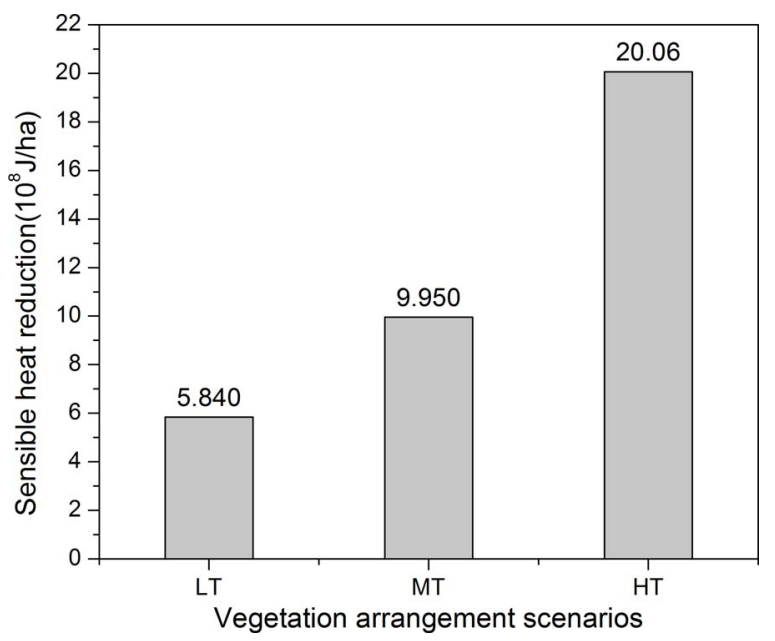

Fig. 9. The energy variations caused by air temperature changes of different vegetation patterns.

heat reduction $\left(20.06 \times 10^{8} \mathrm{~J} / \mathrm{ha}\right)$ due to both evapotranspiration and shading effects (Fig. 9). Fig. 10 represents the percentage of sensible heat reduction of specific hours. All three vegetation arrangement scenarios showed a marked increment in the sensible heat reduction from 11:00, with MT scenario having higher values from 13:00 to 17:00, in comparison with the LT scenario. Interestingly, from 13:00 to 


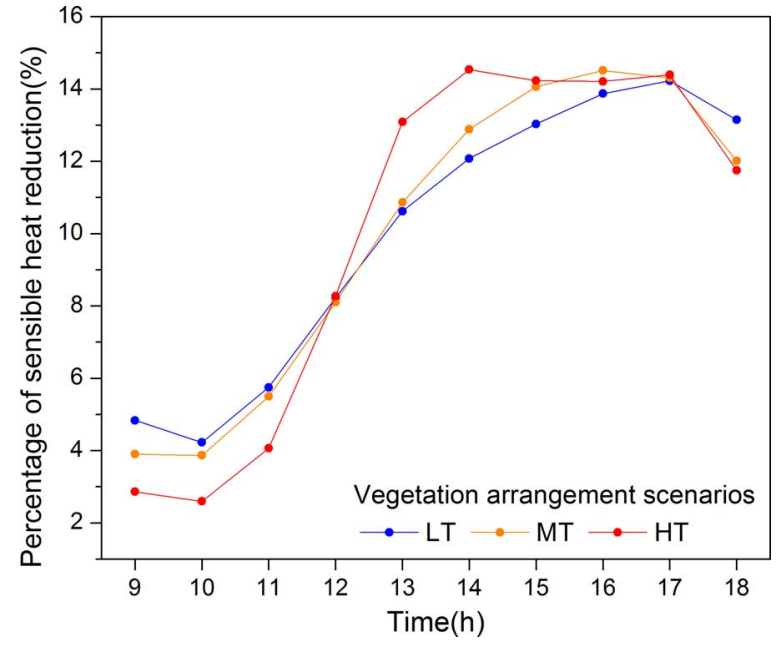

Fig. 10. Percentage of sensible heat reduction of different vegetation patterns

17:00, which was commonly identified as the hottest hours during the summer daytime, the HT scenario contributed its largest sensible heat reduction. The results indicate that the presence of vegetation with reasonable arrangement pattern could improve the effect of urban green spaces by decreasing summer temperatures and sensible heat fluxes into the atmosphere.

\section{Discussion}

\subsection{The effect of added vegetation on air cooling}

The influence of spatial arrangements of urban green spaces on mitigating the thermal environment have been recognized from city to regional scales (Kong et al., 2014; Stone, Vargo, Liu, Hu, \& Russell, 2013; Zhou et al., 2011), but few studies paid attention to the cooling effects of vegetation at the neighborhood scale. In the present study, we analyzed the cooling effects of vegetation in relation to shading effects by adjacent buildings. New trees were virtually planted in locations with low, middle and high incident shortwave radiation at land surfaces. The results showed that adding trees in areas that were strongly influenced by the shading effects of surrounding buildings only provided a marginal cooling effect. In contrast, trees planted in areas that were more exposed to shortwave radiation had a larger cooling effect. This result was due to the trees intercepting solar radiation and mitigating the heating up of land surfaces, which was implemented most effectively in the MT and HT scenarios. With increasing urbanization and projected increasing frequency of heat waves from global warming, added vegetation has been recognized as one of the main strategies to mitigate excess urban heat (Doick, Peace, \& Hutchings, 2014). Many previous studies have analyzed the cooling effect of this strategy using empirical, or numerical methods (Doick et al., 2014; Hamada, Tanaka, \& Ohta, 2013; Millward \& Sabir, 2011; Taleghani et al., 2014; Wong et al., 2007). In this study, we utilized the urban microclimate model ENVI-met to test three vegetation arrangement scenarios at a neighborhood with high-rise buildings in Beijing. The results showed that with $10 \%$ increase in tree coverage in the study area, the air temperature at pedestrian level decreased by $0.22{ }^{\circ} \mathrm{C}$. The cooling rate of added trees in this study was lower than the results from Middel et al. (2014), who used the same model to investigate tree canopy cover impacts on air temperature. They reported a mid-day air temperature reduction of $0.14 \%$ for every one percent increase in canopy cover (Middel et al., 2014). In addition, Skelhorn et al. (2014) compared air temperatures for several greening modification scenarios with different amounts and types of greenspaces (adding 5\% more trees or shrubs). They found that the modification resulted in only minor effects on air temperature. The disparities between these studies and our study might be explained by varied local climates, existing greening situations and different parameterizations and assumptions of microclimate models.

\subsection{The contribution of vegetation allocation on sensible heat reduction}

The heat island phenomenon is mainly caused by enhanced sensible heat that warms up the urban atmosphere. Added vegetation can reduce sensible heat release through ground shading and evapotranspiration, which have been reported in many empirical and measurement studies (Donovan \& Butry, 2009; Georgi \& Dimitriou, 2010; Gillner, Vogt, Tharang, Dettmann, \& Roloff, 2015). We found that the estimated sensible heat reductions from the scenarios LT, MT and HT were $5.84 \times 10^{8} \mathrm{~J} / \mathrm{ha}, 9.95 \times 10^{8} \mathrm{~J} / \mathrm{ha}$ and $20.06 \times 10^{8} \mathrm{~J} / \mathrm{ha}$, respectively, from 9:00 to 18:00, while considering both shading effects and evapotranspiration. Our results are consistent with a previous study on sensible heat reduction produced by green spaces on a summer day. For example, Zhang, Xie, Gao, and Yang (2014) calculated the heat absorbed by urban green spaces in Beijing and found that per hectare green spaces could absorb up to $11.2 \times 10^{8} \mathrm{~J}$ of heat during one hot summer day. Although the added trees of scenario LT were all located in areas that were densely covered by building shadows, the trees still offered approximately $6.0 \times 10^{8} \mathrm{~J} / \mathrm{ha}$ in sensible heat reduction due to evapotranspiration process. Scenarios MT and HT, which had trees that could contribute to sensible heat reduction through both shading effect and evapotranspiration, could lead to further energy saving. Although the lack of data for high-rise building areas and tree canopy coverage make it difficult to estimate the total energy savings from the cooling effect of green space at the whole city scale, the results here demonstrate that adding trees can obviously reduce sensible heat release into the atmosphere, therefore optimizing the configuration of trees for more reduction in sensible heat.

\subsection{How to improve thermal environment comfort by regulating vegetation pattern}

Our results showed that in addition to the widely recognized fact that adding trees can significantly reduce sensible heat release and air temperature, optimizing the spatial arrangement of trees leads to further reduced sensible heat and air temperature at the neighborhood scale. These results have important implications in landscape design at the neighborhood scale. With continuous population growth in China, and many other developing counties, high-rise buildings are commonly used to control urban sprawl. Although high-rise buildings can accommodate more inhabitants and save more land for greening or other purposes to improve people's well-being (Yang et al., 2010), they have several disadvantages in terms of energy consumption and social implications. High-rise building, with its larger building volume, has great influence on the surrounding near surface thermal environment through shading effects. It is reasonable to take advantage of the shading effects when designing the landscape for better cooling effects. According to field measurements, the surface temperatures of concrete roads shaded by buildings were approximately $16^{\circ} \mathrm{C}$ lower than those exposed to solar radiation during mid-day in the summer. This can lead to significantly less reduction of sensible heat fluxes into the atmosphere. With respect to vegetation patterns, we can also use the distribution of shade to optimize the spatial arrangement of vegetation to achieve better cooling effects. Planting trees in areas less shaded by buildings is more desirable for environmental cooling. Our results demonstrate that arrangement strategies for vegetation are effective for lowering air temperature from pedestrian to roof level and decreasing sensible heat fluxes into the atmosphere.

\subsection{Validation and uncertainty of this model}

Environmental simulation models are reasonable approximations of 
reality, and are thus all subjective to varying degree of uncertainty. In general, uncertainty in environmental modeling comes from parameter, data and model's structure. In this sense, modeling without uncertainty is misleading and unscientific since necessary simplifications have been made in various ways in model building and parameters inputting to decrease the computational complexity. For instance, vegetation system is so complex even in urban setting that many simulations employing ENVI-met model choose some typical vegetation on behalf of the vegetation system in the study area, which will introduce a certain level of uncertainty. Measurement error during estimating leaf area density, which is an important parameter of characterizing foliage distribution pattern of vegetation in ENVI-met, will further increase uncertainty.

Previous studies have elaborated on the validation of the ENVI-met model, and we conducted the model validation too by comparing measurement data and ENVI-met results, which showed a good agreement in comparison with some previous studies, e.g. Chow and Brazel (2012), Wang, Berardi, and Akbari (2015). The good performance of a model provides researchers opportunities to conduct exploratory investigations by setting various scenarios, which may be impracticable in reality. In the presented paper, analysis of effects of vegetation layout on local thermal environment have been carried out among greening modification scenarios on the basis of validation of simulation results.

Skelhorn et al. (2014) studied the impact of vegetation types on air and surface temperature by means of ENVI-met modeling. The results showed that $5 \%$ more vegetation only resulted in minor effects on air temperature, without mentioning the cooling rate. We have demonstrated in another study that increasing greenspace coverage has continuous cooling capacity on ambient atmosphere until it reach the threshold, below which every percentage of increase of greenspace coverage will lead to a certain level of air temperature reduction. In the present study, increasing $10 \%$ more greenspaces apparently can result in a certain degree of cooling of atmosphere, differing in cooling rates under different spatial arrangement scenarios. It is reasonable that $10 \%$ more tree coverage have a cooling power less than $0.1^{\circ} \mathrm{C}$ when all the adding trees be covered by building shade, which disenables the trees to intercept the shortwave solar radiation.

We believe that the modeling results presented in this paper have some value on spatial arrangement of greenspaces at neighborhood or block scale. Of course, further studies to support and confirm our results are necessary.

\section{Conclusion}

This paper reports the results of the effect of different spatial arrangements of trees on environmental cooling by integrating modeling with in situ measurements. The research was conducted in a residential neighborhood with high-rise apartment buildings in Beijing. Neighborhood scale study is important for filling the research gap at this specific scale, which is close to the immediate human scale that most often concerns urban environment research. The results showed: (1) Different spatial arrangements led to differentiated effects on intercepting shortwave radiation, which produced variations in air temperature. Scenario HT, which had new trees exposed to solar radiation, contributed to stronger cooling effects than scenario LT, which had new trees located in the shadow of surrounding buildings. The air temperature was $0.22{ }^{\circ} \mathrm{C}$ lower at the pedestrian level. (2) Different spatial arrangements led to significantly different effects of sensible heat reduction, with a maximum difference of $14.84 \times 10^{8} \mathrm{~J} /$ ha in sensible heat reduction among the different scenarios. This research proves that optimized spatial arrangement of greenspaces can both ameliorate thermal environments and mitigate UHI magnitude by reducing air temperature and sensible heat fluxes into atmosphere. Our results have great implications in urban planning and designing at the neighborhood scale.

\section{Acknowledgments}

We thank Prof. Weiqi ZHOU for reviewing and improving the manuscript. We would also thank the anonymous referee for constructive review of this manuscript. The authors express their gratitude to Prof. Michael Bruse for providing the ENVI-met software. This research is supported by National Natural Science Foundation of China (Project No. 41230633).

\section{References}

Berkovic, S., Yezioro, A., \& Bitan, A. (2012). Study of thermal comfort in courtyards in a hot arid climate. Solar Energy, 86, 1173-1186. http://dx.doi.org/10.1016/j.solener. 2012.01.010.

Carfan, A. C., Galvani, E., \& Nery, J. T. (2012). Study of thermal comfort in the City of São Paulo using ENVI-met model. Investigaciones Geográficas, 78, 34-47.

Chow, W. T. L., \& Brazel, A. J. (2012). Assessing xeriscaping as a sustainable heat island mitigation approach for a desert city. Building and Environment, 47(1), 170-181. http://dx.doi.org/10.1016/j.buildenv.2011.07.027.

Connors, J. P., Galletti, C. S., \& Chow, W. T. L. (2013). Landscape configuration and urban heat island effects: Assessing the relationship between landscape characteristics and land surface temperature in Phoenix, Arizona. Landscape Ecology, 28, 271-283. http://dx.doi.org/10.1007/s10980-012-9833-1.

Coutts, A. M., Beringer, J., \& Tapper, N. J. (2007). Impact of increasing urban density on local climate: Spatial and temporal variations in the surface energy balance in Melbourne, Australia. Journal of Applied Meteorology and Climatology, 46(4), 477-493. http://dx.doi.org/10.1175/JAM2462.1.

de Sousa, M. R. C., Montalto, F. A., \& Palmer, M. I. (2016). Potential climate change impacts on green infrastructure vegetation. Urban Forestry \& Urban Greening, 20 , 128-139. http://dx.doi.org/10.1016/j.ufug.2016.08.014.

Doick, K. J., Peace, A., \& Hutchings, T. R. (2014). The role of one large greenspace in mitigating London's nocturnal urban heat island. Science of The Total Environment, 493, 662-671. http://dx.doi.org/10.1016/j.scitotenv.2014.06.048.

Donovan, G. H., \& Butry, D. T. (2009). The value of shade: Estimating the effect of urban trees on summertime electricity use. Energy and Buildings, 41, 662-668. http://dx.doi. org /10.1016/j.enbuild.2009.01.002.

Du, S., Xiong, Z., Wang, Y.-C., \& Guo, L. (2016). Quantifying the multilevel effects of landscape composition and configuration on land surface temperature. Remote Sensing of Environment, 178, 84-92. http://dx.doi.org/10.1016/j.rse.2016.02.063.

Duarte, D. H. S., Shinzato, P., Gusson, C. D. S., \& Alves, C. A. (2015). The impact of vegetation on urban microclimate to counterbalance built density in a subtropical changing climate. Urban Climate, 14(Part 2), 224-239. http://dx.doi.org/10.1016/j. uclim.2015.09.006.

Ge, F., Zhang, L., Wang, J., Tian, G., \& Feng, Y. (2016). Multi-scale temporal charachteristics and periodic analysis of urban heat island-A case study of Beijing. Journal of Beijing Normal University (Natural Science), 52(2), 210-215.

Georgescu, M., Chow, W. T. L., Wang, Z. H., Brazel, A., Trapido-Lurie, B., Roth, M., et al (2015). Prioritizing urban sustainability solutions: Coordinated approaches must incorporate scale-dependent built environment induced effects. Environmental Research Letters, 10(6), 061001.

Georgi, J. N., \& Dimitriou, D. (2010). The contribution of urban green spaces to the improvement of environment in cities: Case study of Chania, Greece. Building and Environment, 45(6), 1401-1414. http://dx.doi.org/10.1016/j.buildenv.2009.12.003.

Ghaffarianhoseini, A., Berardi, U., \& Ghaffarianhoseini, A. (2015). Thermal performance characteristics of unshaded courtyards in hot and humid climates. Building and Environment, 87, 154-168. http://dx.doi.org/10.1016/j.buildenv.2015.02.001.

Gillner, S., Vogt, J., Tharang, A., Dettmann, S., \& Roloff, A. (2015). Role of street trees in mitigating effects of heat and drought at highly sealed urban sites. Landscape and Urban Planning, 143(0), 33-42. http://dx.doi.org/10.1016/j.landurbplan.2015.06. 005 .

Hamada, S., Tanaka, T., \& Ohta, T. (2013). Impacts of land use and topography on the cooling effect of green areas on surrounding urban areas. Urban Forestry \& Urban Greening, 12, 426-434. http://dx.doi.org/10.1016/j.ufug.2013.06.008.

Jia, Q. (2014). Beijing statistics yearbook. Beijing, China: China Statistical Press.

Johansson, L., Onomura, S., Lindberg, F., \& Seaquist, J. (2015). Towards the modelling of pedestrian wind speed using high-resolution digital surface models and statistical methods. Theoretical and Applied Climatology, 1-15. http://dx.doi.org/10.1007/ s00704-015-1405-2.

Kong, F., Yin, H., James, P., Hutyra, L. R., \& He, H. S. (2014). Effects of spatial pattern of greenspace on urban cooling in a large metropolitan area of eastern China. Landscape and Urban Planning, 128, 35-47. http://dx.doi.org/10.1016/j.landurbplan.2014.04. 018.

Li, J., Song, C., Cao, L., Zhu, F., Meng, X., \& Wu, J. (2011). Impacts of landscape structure on surface urban heat islands: A case study of Shanghai, China. Remote Sensing of Environment, 115(12), 3249-3263. http://dx.doi.org/10.1016/j.rse.2011.07.008.

Li, X., Zhou, W., Ouyang, Z., Xu, W., \& Zheng, H. (2012). Spatial pattern of greenspace affects land surface temperature: Evidence from the heavily urbanized Beijing metropolitan area, China. Landscape Ecology, 27, 887-898. http://dx.doi.org/10.1007/ s10980-012-9731-6.

Li, X., Zhou, W., \& Ouyang, Z. (2013). Relationship between land surface temperature and spatial pattern of greenspace: What are the effects of spatial resolution? Landscape and Urban Planning, 114, 1-8. http://dx.doi.org/10.1016/j.landurbplan.2013.02. 
005.

Liu, H., \& Weng, Q. (2008). Seasonal variations in the relationship between landscape pattern and land surface temperature in Indianapolis, USA. Environmental Monitoring and Assessment, 144(1), 199-219. http://dx.doi.org/10.1007/s10661-007-9979-5.

Liu, W., Ji, C., Zhong, J., Jiang, X., \& Zheng, Z. (2007). Temporal characteristics of the Beijing urban heat island. Theoretical and Applied Climatology, 87(1), 213-221. http:// dx.doi.org/10.1007/s00704-005-0192-6.

Meehl, G. A., \& Tebaldi, C. (2004). More intense, more frequent, and longer lasting heat waves in the 21st century. Science, 305(5686), 994. http://dx.doi.org/10.1126/ science.1098704.

Middel, A., Chhetri, N., \& Quay, R. (2014). Urban forestry and cool roofs: Assessment of heat mitigationstrategies in Phoenix residential neighborhoods. Urban Forestry \& Urban Greening, 14(1), 178-186. http://dx.doi.org/10.1016/j.ufug.2014. 09.010.

Millward, A. A., \& Sabir, S. (2011). Benefits of a forested urban park: What is the value of Allan Gardens to the city of Toronto, Canada? Landscape and Urban Planning, 100(3), 177-188. http://dx.doi.org/10.1016/j.landurbplan.2010.11.013.

Oke, T. R. (1982). The energetic basis of the urban heat island. Quarterly Journal of the Royal Meteorological Society, 108(455), 1-24. http://dx.doi.org/10.1002/qj. 49710845502.

Oke, T. R. (1987). Boundary layer climates (2nd Edition). London: Methuen.

Peng, S., Piao, S., Ciais, P., Friedlingstein, P., Ottle, C., Bréon, F.-M., et al. (2012). Surface urban heat island across 419 global big cities. Environmental Science \& Technology, 46(2), 696-703. http://dx.doi.org/10.1021/es2030438.

Skelhorn, C., Lindley, S., \& Levermore, G. (2014). The impact of vegetation types on air and surface temperatures in a temperate city: A fine scale assessment in Manchester, UK. Landscape and Urban Planning, 121, 129-140. http://dx.doi.org/10.1016/j. landurbplan.2013.09.012.

Son, J. Y., Lane, K. J., Lee, J.-T., \& Bell, M. L. (2016). Urban vegetation and heat-related mortality in Seoul, Korea. Environmental Research, 151, 728-733. http://dx.doi.org/ 10.1016/j.envres.2016.09.001.

Srivanit, M., \& Hokao, K. (2013). Evaluating the cooling effects of greening for improving the outdoor thermal environment at an institutional campus in the summer. Building and Environment, 66, 158-172. http://dx.doi.org/10.1016/j.buildenv.2013.04.012.

Stone, B., Vargo, J., Liu, P., Hu, Y., \& Russell, A. (2013). Climate change adaptation through urban heat management in Atlanta, Georgia. Environmental Science \& Technology, 47(14), 7780-7786. http://dx.doi.org/10.1021/es304352e.

Taleghani, M., Sailor, D. J., Tenpierik, M., \& van den Dobbelsteen, A. (2014). Thermal assessment of heat mitigation strategies: The case of Portland State University,
Oregon, USA. Building and Environment, 73, 138-150. http://dx.doi.org/10.1016/j. buildenv.2013.12.006.

Tan, J., Zheng, Y., Tang, X., Guo, C., Li, L., Song, G., et al. (2010). The urban heat island and its impact on heat waves and human health in Shanghai. International Journal of Biometeorology, 54, 75-84. http://dx.doi.org/10.1007/s00484-009-0256-x.

Wang, Z., Zhang, L., Zhao, J., He, Y., \& Li, A. (2011). Thermal responses to different residential environments in Harbin. Building and Environment, 46, 2170-2178. http:// dx.doi.org/10.1016/j.buildenv.2011.04.029.

Wang, Y., Berardi, U., \& Akbari, H. (2015). Comparing the effects of urban heat island mitigation strategiesfor Toronto, Canada. Energy and Building, 114, 2-19. http://dx. doi.org/10.1016/j.enbuild.2015.06.046.

Wang, Z. (2006). A field study of the thermal comfort in residential buildings in Harbin. Building and Environment, 41, 1034-1039. http://dx.doi.org/10.1016/j.buildenv. 2005.04.020.

Wong, N. H., Jusuf, S. K., La Win, A. A., Thu, H. K., Negara, T. S., \& Xuchao, W. (2007) Environmental study of the impact of greenery in an institutional campus in the tropics. Building and Environment, 42, 2949-2970. http://dx.doi.org/10.1016/j. buildenv.2006.06.004.

Wu, W., Zhao, S., Zhu, C., \& Jiang, J. (2015). A comparative study of urban expansion in Beijing, Tianjin and Shijiazhuang over the past three decades. Landscape and Urban Planning, 134, 93-106. http://dx.doi.org/10.1016/j.landurbplan.2014.10.010.

Yan, Q., \& Zhao, Q. (1986). Heat process of building. Beijing: Building Industry Press of China.

Yang, F., Lau, S. S. Y., \& Qian, F. (2010). Summertime heat island intensities in three highrise housing quarters in inner-city Shanghai China: Building layout, density and greenery. Building and Environment, 45, 115-134. http://dx.doi.org/10.1016/j buildenv.2009.05.010.

Yang, L., Yan, H., Xu, Y., \& Lam, J. C. (2013). Residential thermal environment in cold climates at high altitudes and building energy use implications. Energy and Buildings, 62, 139-145. http://dx.doi.org/10.1016/j.enbuild.2013.02.058.

Zhang, B., Xie, G., Gao, X., \& Yang, Y. (2014). The cooling effect of urban green spaces as a contribution to energy-saving and emission-reduction: A case study in Beijing, China. Building and Environment, 76, 37-43. http://dx.doi.org/10.1016/j.buildenv. 2014.03.003.

Zhou, W., Huang, G., \& Cadenasso, M. L. (2011). Does spatial configuration matter? Understanding the effects of land cover pattern on land surface temperature in urban landscapes. Landscape and Urban Planning, 102, 54-63. http://dx.doi.org/10.1016/j. landurbplan.2011.03.009. 